\title{
Study on the microbiological potential of biofertilizer applied on Brassica oleracea (cauliflower)
}

\author{
Mrityunjoy Acharjee* \\ Department of Microbiology, Stamford University Bangladesh, 51 Siddeswari Road, Dhaka 1217, Bangladesh
}

Received 13 July 2017/Accepted 02 September 2017

\begin{abstract}
Plant nutrients are vital component of sustainable agriculture as they are essential for the production of crops and healthy food. Chemical fertilizer or pesticides may have huge influence to increase the heavy metal and resistant microbes in soil as well as in crops. In order to provide an experimental evidence on the positive impact of bio-fertilizer instead of chemical fertilizer on agricultural field, present study attempted to collect 50 samples of Brassica oleracea (25 were treated with bio-fertilizer and 25 were chemically treated) from different agricultural land of rural area in Bangladesh. The samples were processed to examine the microbiological and clinical aspects of both bio-fertilizer and chemical fertilizer on vegetables through several common, traditional and replicable cultural and biochemical tests. Both samples were found to be contaminated with total viable bacteria and fungi up to the range $10^{8} \& 10^{6} \mathrm{cfu} / \mathrm{g}$, respectively. The elevated range of pathogenic contamination (Staphylococcus spp., Bacillus spp., Pseudomonas spp.) was found in both samples within the range of $10^{2}$ to $10^{6} \mathrm{cfu} / \mathrm{g}$. In case of biofertilizer treated vegetable the contamination of Staphylococcus spp. was prominent up to $10^{6} \mathrm{cfu} / \mathrm{g}$ and the same existence was found for chemically treated vegetable. Bacillus spp. and Pseudomonas spp. were found $10^{4} \& 10^{5} \mathrm{cfu} / \mathrm{g}$, respectively in biofertilizer treated vegetable while the contamination was noticed up to $10^{2} \& 10^{4} \mathrm{cfu} / \mathrm{g}$ in chemically treated vegetable respectively. Another important era of this study is drug resistant pattern, most of the isolates exhibited resistance against commonly used antibiotics while several isolates were noted to be multi-drug resistant (MDR). The drug resistance strains were remarkably high in chemically treated vegetable whereas maximum antibiotics were extremely effective against the bacteria isolated from biofertlizer treated vegetable.
\end{abstract}

Key words: Biofertlizer; Chemical fertilizer; Vegetable; MDR; Public health

Improper disposal of wastes such as land disposal of municipal and industrial wastes, automobile emissions, mining activity, as well as applications of fertilizers and pesticides are great concerns in today's world (1-4). Composting is considered as the only eco-friendly and natural process of recycling or microbial decomposition method of organic matter under controlled conditions which can convert this huge amount of wastes into a valuable resource (5-7). Since composting is a microbiological process, different types of mesophilic, thermotolerant and thermophilic aerobic microorganisms (e.g. bacteria, actinomycetes, yeasts, and fungi) are involved in the composting process (6-8). Comparing to chemical fertilizer or mineral fertilizer, organic manure or compost is an inexpensive biofertilizer that increases soil organic matter, the water-holding capacity of coarse-textured sandy soils, improves drainage in fine-textured clay soils, provides a source of slow release nutrients, reduces water erosion, and promotes growth of earthworms and other beneficial soil organisms (9).

However, previous studies have reported that several

*Corresponding Author: Mailing address. Mrityunjoy Acharjee, Senior Lecturer, Department of Microbiology, Stamford University Bangladesh, 51 Siddeswari Road, Dhaka 1217, Bangladesh, Bangladesh; E-mail: mrityunjoy_111@yahoo.com. food-born diseases were associated with the consumption of raw fruits \& vegetables contaminated by manure (10-13). The major reason behind the contaminated vegetables and fruits as well as accumulation of heavy metals in the soils and vegetables is the long-term use of excessive chemical fertilizers and organic manures in the bare vegetable field and the greenhouse vegetable field (14). High fertilizer applications causes acid atmospheric deposition and decrease in $\mathrm{pH}$ and thus increases heavy metal availability, aggravating the problem of deteriorating food quality, metal leaching, and impacts on soil organisms (15). So, the agricultural or domestic use of this manure can increase the risk of disease transmission by direct contact of humans with the material or by contamination of food crops or by adding to environmental contamination which may maintain diseases in the food of animal population (16). Moreover, transmission of drug resistance virulent genes of these soil microflora can act as carrier in the transmission of disease to human through the environmental factors such as water, food residue and waste material (17-20). Therefore, our current investigation attempted to ponder the microbiological aspect of biofertilizer and chemical fertilizer on raw Brassica oleracea along with the drug resistance pattern of the isolates from vegetable. 


\section{MATERIALS AND METHODS}

Study area, sampling and sample processing. Total 50 samples of Brassica oleracea ( 25 were grown with bio-fertilizer and 25 were grown using chemical fertilizer) were randomly collected from different rural area in Bangladesh during January 2014-March 2014 following standard protocol (21).

Estimation of total viable bacteria and fungi. The enumeration was performed by using $0.1 \mathrm{ml}$ of each sample from the dilution $10^{-3}$ was spread onto nutrient agar (NA) and Sabouraud Dextrose Agar (SDA) for total viable bacteria (TVB) and total fungal load, respectively. After that the nutrient agar (NA) and Sabouraud Dextrose Agar (SDA) plates were incubated at $37{ }^{\circ} \mathrm{C}$ for 24 hours and at $25{ }^{\circ} \mathrm{C}$ for 48 hours for the detection of total viable bacteria (TVB) and total fungus respectively according to the standard guideline (22). Estimation of coliform count and fecal coliform count (FCC). An aliquot of $0.1 \mathrm{ml}$ of each sample was spread on to MacConkey agar, and membrane fecal coliform agar plates for the estimation of coliform (E. coli and Klebsiella spp.) and fecal coliform (FCC) respectively. For coliform count, all plates were incubated at $37{ }^{\circ} \mathrm{C}$ for 24 hours while for estimating the fecal coliforms, incubation was carried out at $44.5{ }^{\circ} \mathrm{C}$ for 24 hours. Eosin methylene blue agar media was further used for the observation of production of green metallic sheen (if any) to ensure the specific characteristic of $E$. coli strains $(17,18)$.

Estimation of Staphylococcus spp., Pseudomonas spp. Clostridium spp. Bacillus spp. and Listeria spp. Same amount of samples as described above was spread on to mannitol salt agar, cetrimide agar Starch agar and Listeria media for the isolation of $S$. aureus, Pseudomonas spp., Bacillus spp and Listeria spp., respectively. Afterwards, plates were incubated at $37{ }^{\circ} \mathrm{C}$ for 24 hours. For the isolation of clostridium $1 \mathrm{ml}$ of each blended sample were mixed in sterile normal saline in a ratio of $1: 8$ followed by heating at $80{ }^{\circ} \mathrm{C}$ for 15 minutes in order to kill vegetative cells of the microorganisms $(17,18)$. Furthermore, $1 \mathrm{ml}$ of each samples were introduced into $9 \mathrm{ml}$ of fluid thioglycolate broth and incubated for 4 hours at $37{ }^{\circ} \mathrm{C}$. Then $0.1 \mathrm{ml}$ of each sample from this enriched broth was poured on Clostridium isolation agar plates according to pour plate method and were incubated at $37{ }^{\circ} \mathrm{C}$ in anaerobic condition for 48 hours (23).

Estimation of Salmonella spp., Shigella spp. and Vibrio spp. For the isolation of VBNC Salmonella spp., Shigella spp., and Vibrio spp. 1ml of each samples was inoculated into Alkaline peptone water (APW) and Selenite cystain Broth (SCB) for enrichment and incubated at $37^{\circ} \mathrm{C}$ up to 6 hours. Afterward, 0.1 $\mathrm{ml}$ of each sample from the broth was introduced on selective media such as Salmonella, Shigella agar and the Thiosulfate Citrate Bile Salt Sucrose agar media respectively and plates were incubated at $37^{\circ} \mathrm{C}$ for 24 hours (24).

Confirmatory Biochemical tests. For the final identification of all isolates, several biochemical tests were performed including the triple sugar iron test, motility indole urease test, methyl red test, Voges Proskauer test, indole utilization test and the oxidase test (table 2) (22).

Determination of antimicrobial susceptibility of the isolates. The pathogenic isolates were examined for antibiotic susceptibility traits (either drug resistant or sensitive) by disc diffusion assay on Mueller-Hinton agar (Difco, Detroit, MI) against commonly used antibiotics following the standard protocol $(23,25,26)$. Lawns of bacterial suspensions including Escherichia coli, Pseudomonas spp., Vibrio spp., Staphylococcus spp.and Salmonella spp. (turbidity compared with the $\mathrm{McF}$ arland standard $\mathrm{OD}_{600^{-}}-0.5$ ) were prepared and introduced on to Muller Hinton agar. Antibiotics used in the study included polymixin B (300 unit), Kanamycine $(30 \mu \mathrm{g})$, methicillin $(30 \mu \mathrm{g})$, streptomycin $(10 \mu \mathrm{g})$, vancomycine $(30 \mu \mathrm{g})$, gentamycine $(10 \mu \mathrm{g})$, nalidixic acid $(30 \mu \mathrm{g})$, azythromycine $(15 \mu \mathrm{g})$, penicillin $\mathrm{G}(10 \mu \mathrm{g})$, erythromycin $(15 \mu \mathrm{g})$, amoxicillin (30 $\mu \mathrm{g})$, ceftriaxon $(30 \mu \mathrm{g})$, ciprofloxacin $(5 \mu \mathrm{g})$, ampicillin $(10 \mu \mathrm{g})$, tetracycline $(30 \mu \mathrm{g})$, chloramphenicol $(30 \mu \mathrm{g})$ and cefixime $(5 \mu \mathrm{g})$. All plates were incubated at $37{ }^{\circ} \mathrm{C}$ for $12-18$ hours and examined for formation of the zone of inhibitions (mm) (27).

\section{RESULTS AND DISCUSSIONS}

In developing countries like Bangladesh agriculture sector plays an important role for developing the socioeconomic status of the farmer as well as the country (28). To ensure the better production of crops, reduce the health and environmental risk and soil degradation scientists suggested that the use of agriculture fertilizer (bio-fertilizer) is more effective than the chemical fertilizer (29). Present study showed that the both samples were found to be highly contaminated with total viable bacteria and fungi up to the range $10^{8} \&$ $10^{6} \mathrm{cfu} / \mathrm{g}$ respectively (Table 1 ).

TABLE 1. Comparative microbial load (cfu/g) within the biofertilizer treated vegetables and chemical fertilizer treated vegetable

\begin{tabular}{lcc}
\hline Microorganism & $\begin{array}{c}\text { Biofertilizer treated } \\
\text { (Brassica oleracea }) \\
\mathbf{n = 2 5}\end{array}$ & $\begin{array}{c}\text { Chemical treated } \\
(\text { Brassica oleracea }) \\
\mathbf{n}=\mathbf{2 5}\end{array}$ \\
\hline TVBC & $6.3 \times 10^{7}$ & $2.6 \times 10^{8}$ \\
Fungi & $6.6 \times 10^{6}$ & $1.3 \times 10^{5}$ \\
Coliform & 0 & 0 \\
Fecal coliform & 0 & 0 \\
Staphylococcus spp. & $1.0 \times 10^{6}$ & $1.5 \times 10^{6}$ \\
Bacillus spp. & $3.3 \times 10^{4}$ & $2.7 \times 10^{2}$ \\
Pseudomonas spp. & $1.4 \times 10^{4}$ & $2.1 \times 10^{3}$ \\
Vibrio spp. & 0 & 0 \\
Salmonella spp. & 0 & 0 \\
Shigella spp. & 0 & 0 \\
Listeria spp. & 0 & 0 \\
Clostridium spp. & 0 & 0 \\
\hline TVBC - Tot & 0 &
\end{tabular}

TVBC $=$ Total viable bacterial count

The average counts have been shown and the results were reproducible

Although the samples were free from coliform, fecal coliform bacteria but existences of pathogenic flora such as Staphylococcus spp., Bacillus spp., Pseudomonas spp., were also found in all the samples of both biofertilizer treated and chemically treated (Table 1). Vibrio spp., Salmonella spp., Shigella spp., Listeria spp. and Clostridium spp. were not cultivated from the both samples.

In case of biofertilizer treated vegetable the contamination of Staphylococcus spp. was prominent up to $10^{6} \mathrm{cfu} / \mathrm{g}$ and the same existence was found for chemically treated vegetable. Bacillus spp. and Pseudomonas spp. were found $10^{4} \& 10^{5} \mathrm{cfu} / \mathrm{g}$ respectively in biofertilizer treated vegetable while the contamination was noticed up to $10^{2} \& 10^{4} \mathrm{cfu} / \mathrm{g}$ in chemically treated vegetable respectively (Table 1). All the isolates found in the tested samples were biochemically confirmed through several test. As described in previous studies the excessive implementation of chemical fertilizer and organic manure are directly responsible to reduce the soil quality, nutritive value of the crops and shelf life (30). However, several researchers have demonstrated that the combined use of chemical and biofertilizer has beneficial impact on the mitigation of secondary and micronutrients in fields and also these heavy metals or biomass may remain in vegetables and fruits (31-35).

Frequency of antibiotic resistant isolates. The drug resistant profile of the isolates from both cases was introduced against 17 antibiotics. All the isolates found in this study showed resistance against at least two 
antibiotics but the resistance properties of the isolated bacteria were very high in chemically treated vegetable respectively (Table 2). All the isolates found in the tested samples were biochemically high in chemically treated vegetable (Table 2). In case of biofertilizer treated sample, Staphylococcus spp. and Pseudomonas spp. were found to be $100 \%$ resistant against Penicillin G, Amoxicillin, Ampicillin, Tetracycline and Methicillin, Penicillin G, Ampicillin respectively while Bacillus spp. shower $100 \%$ resistance against Polymixin B, Penicillin G and Amoxicillin. Maximum antibiotics were highly effective against the bacteria isolated from Biofertilizer treated vegetable (Table 1). Conversely, all the isolates were found to be resistance against almost all antibiotics in case of chemically treated vegetables (Table 2). Staphylococcus spp. was found sensitive only against Methicillin, Streptomycin Gentamycin \& Azythromycin and Bacillus spp. was sensitive against Streptomycin, Gentamycin and Azythromycin. Pseudomonas spp. was found to be sensitive only against Streptomycine and Gentamycin
(Table 2). All 3 pathogen isolated from chemically treated vegetable showed their resistance against multiple drugs which indicated that the strains were multi drug resistant (MDR). Above describe findings clearly demonstrated that the implementation of chemical fertilizer on vegetable significantly increases the bacterial resistance rather than the biofertilize. Consumption of these drug resistant bacteria through different vegetable and fruits may lead serious food born illness in human and also reduce the natural immunity of the individual.

The resistance might be due to genetic, mechanistic or epidemiologic considerations, cross resistance prominence and metabolic changes (36-38). According to the microbial genetic study, mutation is one of the major reasons which can accelerate the bacterial resistance by altering the genetic code in DNA due to the influence of several chemical agents and transferring the resistant gene to sensitive one from a virulent pathogen via conjugation (38).

Finally, in addition to the microbiological prospective of biofertilizer and chemical fertilizer, it's necessary

TABLE 2. Antibiotic resistance/sensitivity pattern of the isolates

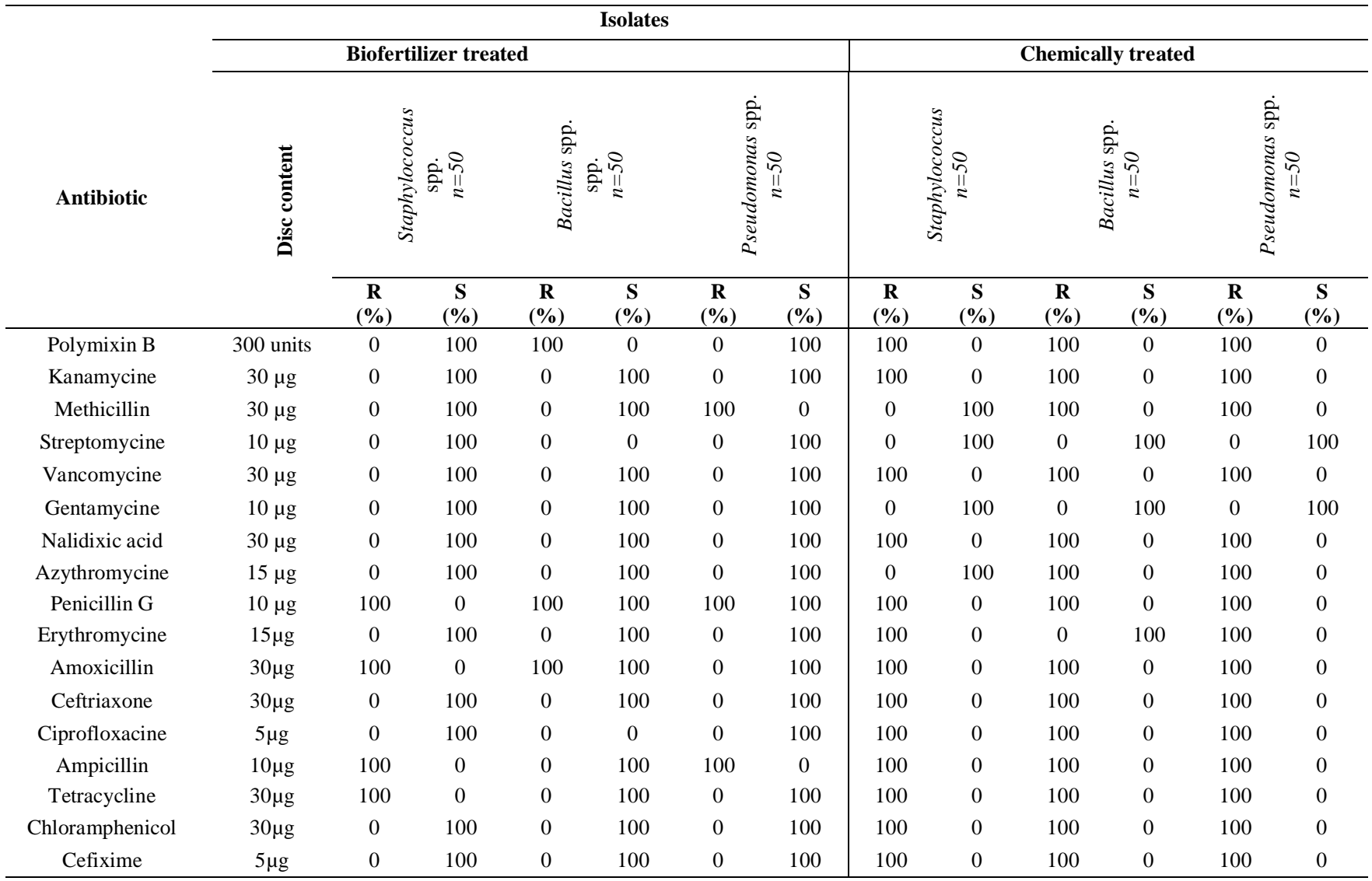

$\mathrm{R}=$ Resistant

$\mathrm{S}=$ Sensitive

All the experiments have been done three times and the results were reproducible. Average data have been shown. 


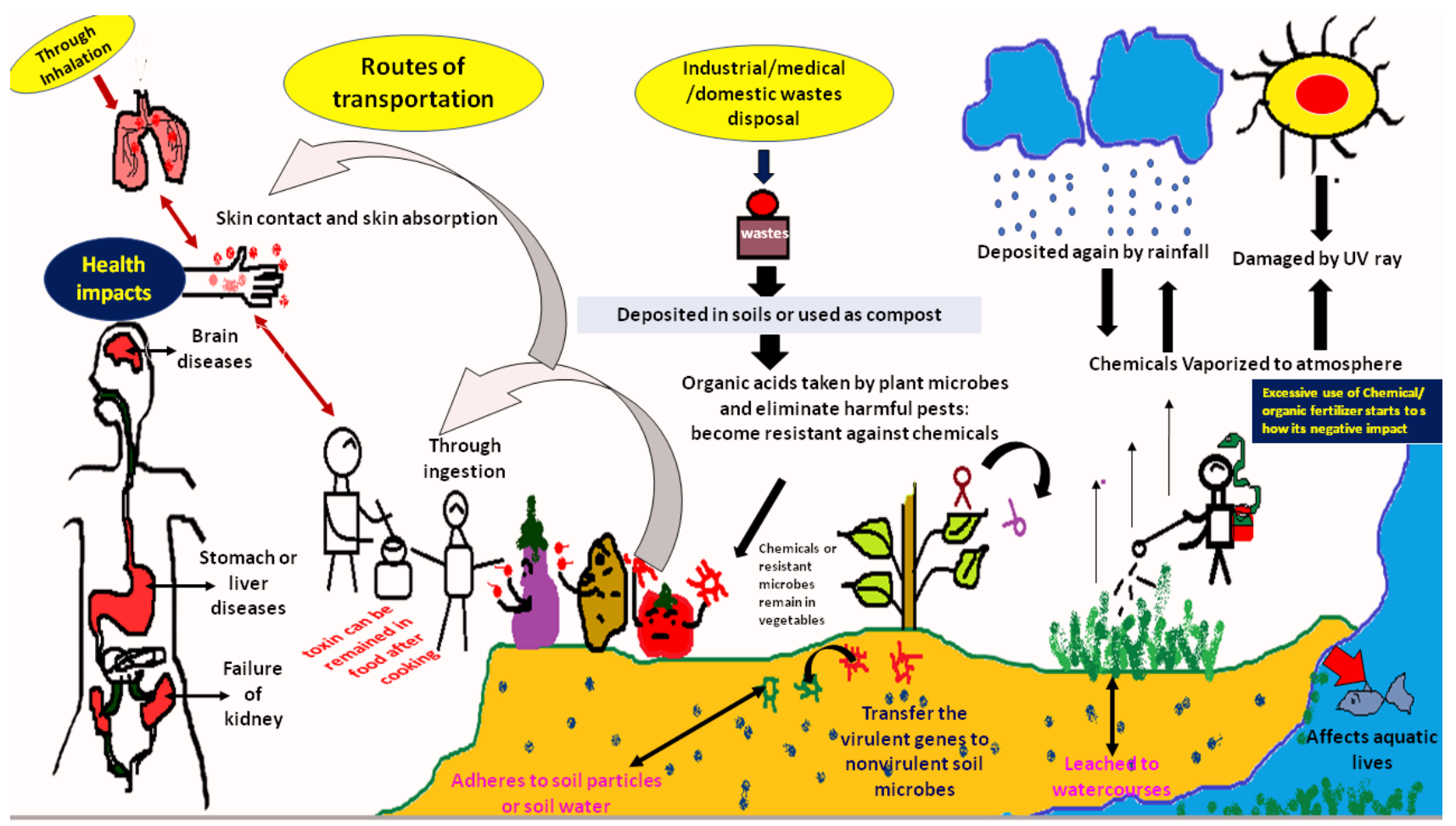

FIG. 1. Effects of chemical fertilizer on agriculture field as well as environment. Excessive use of chemical fertilizers in the agricultural fields may pose a negative influence on environment; some amounts of these fertilizers become vaporized in the open atmosphere in the presence of sunlight or

UV ray. These vaporized chemicals can be deposit again in the soil by rainfall or acid rain. Some are leached into the soil and watercourses and affects aquatic lives of nearest river.

to provide a complete schema on the bad impact of chemical fertilizer towards the soil as well as environment. This study attempted to demonstrate a simple overview by which researcher/expert can explain the whole things to the general people as well as the farmers very effortlessly (Figure 1).

Excessive use of chemical fertilizers in the agricultural fields may pose a negative influence on environment; some amounts of these fertilizers become vaporized in the open atmosphere in the presence of sunlight or UV ray. These vaporized chemicals can be deposit again in the soil by rainfall or acid rain. Some are leached into the soil and watercourses and affects aquatic lives of nearest river. In the presence of these chemicals for long periods in the soil, soil bacteria can become virulent by developing resistant genes against these chemicals. Similar results can found in case of deposition of wastes in the soil. On the contrary, plant microbes uptake the chemicals or organic acids from the fertilizer and become virulent (Figure 1). When human ingest these vegetables, the virulent microbes are also introduced in their body through ingestion, skin contact (handling) or inhalation. This can cause severe health impacts like blood disorder, brain disease or failure of kidney.

\section{CONCLUSION}

Increased crop production and soil fertility largely relies on the type of fertilizers used in the land as supplement nutrients for plants. Biofertilizers differ from chemical and organic fertilizers for its availability, simple production procedure and low cost rate. Regardless of methods, microbes present in biofertilizer will decline and be eliminated in a very short time after application in the field. At present, overuse or misuse of chemical fertilizers in agriculture is one of the major motive of environmental deterioration as well as contaminated food products. Overall, the present study revealed that biocompost or biofertilizer imparted no added effect in context of microbiological quality on the vegetables on which they were applied. In this point of view, it can be concluded that biocompost can easily be applied to the field instead of chemical fertilizer considering its economic benefit together with environmental sustainability as might be pretense by the chemical fertilizers. Finally, current investigation revealed that the increasing state of drug resistant bacteria due to the improper use of chemicals in agricultural land might responsible for serious obstacle in proper medication of the diseases which could potentially become a public health threat. Efficient plant nutrition 
management should ensure both enhanced and sustainable agricultural production and safeguard the environment. Chemical, organic or microbial fertilizer has its advantages and disadvantages in terms of nutrient supply, soil quality and crop growth. Developing a suitable nutrient management system that integrate the use of these kinds of fertilizers may be a challenge to reach the goal of sustainable agriculture; however much research is still needed especially for the agricultural based country to ensure the agriculture linked health safety.

\section{REFERENCES}

1. Nouri J, Mahvi AH, Jahed GR, Babaei A. 2008. A regional distribution pattern of groundwater heavy metals resulting from agricultural activities. Environmental Geology. 55: 1337-1343.

2. Tu C, Zheng CR, Chen HM. 2000. Effect of applying chemical fertilizers on forms of lead and cadmium in red soil. Chemosphere. 41: 133-138. doi:10.1016/ S0045-6535(99)00400-2.

3. Selene CH, Chou J, De Rosa CT. 2003. Case studies-Arsenic International Journal of Hygiene. 4-5: 381-386.

4. Wouters IM, Spaan S, Douwes J, Doekes G, Heederik D. 2005. Overview of personal occupational exposure levels to inhale dust, endotoxin, $\beta$ (1-3)-glucan and fungal extracellular polysaccharides in the waste management chain. Ann. Occup. Hyg. 47: 1-15.

5. Gajdos R. 1992. The use of organic waste materials as organic fertilisersrecycling of plant nutrients. Acta Hortic. 302: 325-331.

6. Taiwo LB, Oso BA. 2004. Influence of composting techniques on microbial succession,temperature and $\mathrm{pH}$ in a composting municipal solid waste. African Journal of Biotechnology. 3 (4): 239-243.

7. Peters S, Koschinsky S, Schwieger F, Tebbe CC. 2000. Succession of microbial communities during hot composting as detected by PCR-singlestrand-conformation polymorphism-based genetic profiles of smallsubunit rRNA genes. Appl. Environ. Microbiol. 66 (3): 930-936.

8. Beffa T, Blanc M, Marilley L, Fisher JL, Lyon PF, Aragno M. 1996 Taxonomic and metabolic microbial diversity during composting. In The Science of Composting, Part 1, eds. 149-161.

9. Dauda SN, Ajayi FA, Ndor E. 2008. Growth and yield of water melon (Citrullus lanatus) as affected by poultry manure application. J. Agric. Soc. Sci. 4: 121-124.

10. Cieslak PR, Barrett TJ, Griffin PM, et al. 1993. Escherichia coli O157:H7 infection from a manured garden. The Lancet. 342:367.

11. Chapman PA, Siddons CA, Manning J, et al. 1997. An outbreak of due to verocytotoxin-producing Escherichia coli $\mathrm{O} 157: \mathrm{H} 7$ in four families: the influence of laboratory methods on the outcome of the investigation. Epidemiol Infect. 119:113-119.

12. Itoh Y, Sugita-Konishi Y, Kasuga F. 1998. Enterohemorrhagic Escherichia coli $\mathrm{O} 157: \mathrm{H} 7$ present in radish sprouts. Applied Environmental Microbiology. 64: 1532-1535.

13. Little C, Roberts D, Youngs E, et al. 1999. Microbiological quality of retail imported unprepared whole lettuces: a PHLS food working group study. J Food Pro. 62: 325-328

14. Huang SW, Jin JY. 2008. Status of heavy metals in agricultural soils as affected by different patterns of land use. Environmental Monitoring and Assessment. 139 (1-3), 317-327. doi:10.1007/s10661-007-9838-4.

15. De Vries W, Römkens PFAM, Van Leeuwen T, Bronswijk JJB. 2002. Heavy metals. In: P. M. Haygarth \& S. C. Jarvis (Eds.), Agriculture, hydrology and water quality. 107-132. UK: CABI.

16. Jones P, Martin M. 2003. A Review of the Literature on the Occurance and Survival of Pathogens of Animals and Humans in Green Compost.
17. Chowdhury FFK, Acharjee M, Noor R. 2016. Maintenance of Environmental Sustainability Through Microbiological Study of Pharmaceutical Solid Wastes. CLEAN - Soil, Air,Water 44: 309-316.

18. Noor R, Acharjee M, Ahmed T, Das KK, Paul L, Munshi SK, et al. 2013. Microbiological analysis of major sea fish collected from local markets in Dhaka city, Bangladesh. J Microbiol. Biotech. Food Sci. 2: 2420-2430.

19. Tenover FC. 2006. Mechanisms of Antimicrobial Resistance in Bacteria. Am. J. Med. 119: 3-10.

20. Allerberger F, Mittermayer H. 2008. Antimicrobial stewardship. Clin Microbiol. Infect. 14: 197-199.

21. American Public Health Association (APHA). 1998. Standard Methods for the Examination of Water and Wastewater. American Public Health Association, Washington, D.C.

22. Cappuccino JG, Sherman N. 1996. Microbiology - A laboratory manual. The Benjamin/Cummings Publishing Co., Inc., Menlo Park, California.

23. Acharjee M, Jahan F, Rahman F, Noor R. 2014. Bacterial Proliferation in Municipal Water Supplied in Mirpur Locality of Dhaka City, Bangladesh. Clean - Soil, Air, Water. 42 (4): 434-441.

24. Acharjee M, Rahman F, Beauty SA, Feroz F, Rahman MM, Noor $\mathbf{R}$ 2012. Microbiological study on supply water and treated water in Dhaka city. S. J. Microbial. 1 (1): 42-45

25. Bauer AW, Kirby WMM, Sherris JC, Tierch M. 1966. Antibiotic susceptibility testing by a standardized single disc method. Ame. J. Clin. Patholog. 45 (4): 493-496.

26. Munshi SK, Rahman MM, Noor R. 2012. Detection of virulence potential of diarrheagenic Escherichia coli isolated from surface water rivers surrounding Dhaka city. J. Bang. Acad. Sci. 36 (1): 109-121.

27. Ferraro MJ, Craig WA, Dudley MN. 2001. Performance standards for antimicrobial susceptibility testing. NCCLS, Pennsylvania, USA.

28. Huda MdN, Habib A. 2014. Social Factors Affecting Modern Inputs in Agriculture and Non-farm Activities in Village Shimulia. 13 (1): 1-14

29. Mishra P, Dash D. 2014. Rejuvenation of Bio-fertilizers for Sustainable Agriculture and Economic Development, Consilience. The Journal of Sustainable Development. 11 (1): 41-61.

30. Cohen AT, Mariela P, Rubén B, Patricia P. 2007. Azospirillum Brasilense and ABA Improve Growth in Arabidopsis. International Plant Growth substances Association 19th annual meeting Puerto Vallarta, Mexico-July. 2125 .

31. Gaby WL. 1975. Evaluation of health hazards associated with solid waste/sewage sludge mixtures. EPA-670/2-75-023. US Environmental Protection Agency, National Environmental Research Center, Office of Research and Development, Cincinnati, Ohio, USA.

32. Dutta S, Pal R, Chakeraborty A, Chakrabarti K. 2003. Influence of integrated plant nutrient supply system on soil quality restoration in a red and laterite soil. Archives of Agronomy and Soil Science. 49: 631-637.

33. Sundara B, Natarajan V, Hari K. 2002. Influence of phosphorus solubilizing bacteria on the change in soil available phosphorus and sugarcane and sugar yields. Field Crops Research. 77 (1): 43-49.

34. Young CC, Lai WA, Shen FT, Hung MH, Hung WS, Arun AB. 2003. Exploring the microbial potentially to augment soil fertility in Taiwan. In Proceedings of the 6th ESAFS International Conference: Soil Management Technology on Low Productivity and Degraded Soils, Taipei, Taiwan. 25-27.

35. Young CC, Lai WA, Shen FT, Huang WS, Arun AB, 2004 Characterization of multifunctional biofertilizer from Taiwan and biosafety considerations. International Symposium on Future Development of Agricultural Biotechnology Park. The symposium series for celebrating the establishment of the Agricultural Biotechnology Park, Council of Agriculture, Executive Yuan, \& the 80th Anniversary of National Pingtung University of Science and Technology.

36. Bennett PM. 2008. Plasmid encoded antibiotic resistance: Acquisition and transfer of antibiotic resistance genes in bacteria. Bri. J. Pharma. 153 (1): 347 357.

37. Canton R. 2009. Antibiotic resistance genes from the environment: A perspective through newly identified antibiotic resistance mechanisms in clinical setting. Euro. Soc. Clin. Microbiol. Infect. Dis. 15 (1): 20-25.

38. Hung DT, Kaufman BB. 2010. The Fast Track to Multidrug Resistance. Mol. Cell Biol., 37 (3): 297-298. 